\title{
A New Plant Wide Modelling Approach for the Reduction of Greenhouse Gas Emission from Wastewater Treatment Plants
}

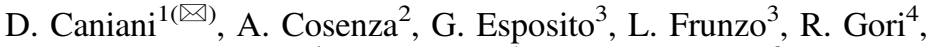 \\ G. Bellandi ${ }^{4}$, M. Caivano ${ }^{1}$, and G. Mannina ${ }^{2}$ \\ ${ }^{1}$ University of Basilicata, School of Engineering, \\ Viale dell'Ateneo Lucano N.10, Potenza, Italy \\ ${ }^{2}$ University of Palermo, Department of Civil, Environmental, \\ Aerospace and Materials Engineering, Viale delle Scienze, 90128 Palermo, Italy \\ ${ }^{3}$ University of Cassino and the Southern Lazio, \\ Department of Civil and Mechanical Engineering, \\ Via Di Biasio, 43, 03043 Cassino, FR, Italy \\ ${ }^{4}$ University of Florence, Department of Civil and Environmental Engineering, \\ Via S. Marta 3, 50139 Florence, Italy
}

\begin{abstract}
Recent studies about greenhouse gas (GHG) emissions show that sewer collection systems and wastewater treatment plants (WWTPs) are anthropogenic GHG potential sources. Therefore, they contribute to the climate change and air pollution. This increasing interest towards climate change has led to the development of new tools for WWTP design and management. This paper presents the first results of a research project aiming at setting-up an innovative mathematical model platform for the design and management of WWTPs. More specifically, the study presents the project's strategy aimed at setting-up a plant-wide mathematical model which can be used as a tool for reducing/ controlling GHG from WWTP. Such tool is derived from real data and mechanicistic detailed models (namely, Activated Sludge Model's family). These latter, although are a must in WWTP modelling, hamper a comprehensive and easy application due to complexity, computational time burdens and data demanding for a robust calibration/application. This study presents a summary of the results derived from detailed mechanistic models which have been applied to both water and sludge line of a WWTP: primary treatment, biological reactor, secondary settler, membrane bioreactor, sludge digester etc. The project is organized in overall four research units (RUs) which focus each on precise WWTP units.
\end{abstract}

Keywords: GHG emissions $\cdot$ Mathematical modelling $\cdot$ Wastewater treatment plants

\section{Introduction}

Wastewater treatment plants (WWTPs) are responsible for the emission of greenhouse gases (GHGs), such as nitrous oxide $\left(\mathrm{N}_{2} \mathrm{O}\right)$, methane $\left(\mathrm{CH}_{4}\right)$, and carbon dioxide $\left(\mathrm{CO}_{2}\right)$. Efforts for monitoring and accounting for GHG emissions from WWTPs are of 
increasing interest (Daelman et al. 2013; Caniani et al. 2015; Caivano et al. 2016; Mannina et al. 2016c).

The mathematical modelling of activated sludge (AS) treatment is the most important tool for developing control strategies and designing WWTPs. In 1982, the International Association on Water Pollution Research and Control (IAWPRC) established a Task Group on Mathematical Modelling for Design and Operation of Activated Sludge Processes. From 1982 at now, mathematical modelling has widely developed, evolved and combined with the control systems (Olsson 2012). However, there is still work to be done to link this knowledge acquired and integrate it at system-wide framework level.

Moreover, $\mathrm{N}_{2} \mathrm{O}$ emission from WWTP represents a frontier of Research that still requires to be crossed. $\mathrm{N}_{2} \mathrm{O}$ emissions primarily occur in aerated zones owing to the fact that the main contributors are active stripping and ammonia-oxidizing bacteria, rather than heterotrophic denitrifiers. Indeed, despite during the last years efforts have been done to better understand the key elements on the $\mathrm{N}_{2} \mathrm{O}$ production/modelling, several questions remain scarcely understood (Caniani et al. 2015; Mannina et al. 2016c).

In this work, we present the key methodological features and some of the results of a research project aiming at developing an innovative simulation platform for the design and management of WWTPs. Such a platform is aimed at reducing the energy consumption and pollutant/residue emissions (namely, residual pollutants in the effluent, sludge and GHGs) from WWTPs. Overall, the project is constituted by four research units (RUs): University of Palermo (RU1), University of Basilicata (RU2), University of Cassino and Southern Lazio (RU3) and University of Florence (RU4).

\section{Materials and Methods}

\subsection{Research Unit 1}

The objective of RU1 is the study of the chemical/physical/biological phenomena of advanced wastewater treatment systems, through designing, building and operating an MBR plant at pilot scale aimed at removing nutrients (Mannina et al. 2016b). Three mechanistic integrated membrane bioreactor (MBR) mathematical models (namely, Model I, Model II and Model III) all of the Activated Sludge Model (ASM) family (Henze et al. 2000) have been implemented, including the simulation of $\mathrm{N}_{2} \mathrm{O}$ and $\mathrm{CO}_{2}$ emissions

Model I has been applied to a pilot plant having a pre-denitrification scheme (anoxic and aerobic reactors in series) and equipped with an hollow fiber membrane for the solid - liquid separation $\left(20 \mathrm{~L} \mathrm{~h}^{-1}\right.$ of saline industrial wastewater were considered as influent) (Mannina et al. 2016a). Model II and III have been applied to a pilot plant with a University Cape Town (UCT) (anaerobic, anoxic and reactors in series) MBR scheme $\left(20 \mathrm{~L} \mathrm{~h}^{-1}\right.$ of real wastewater were considered as influent) (Mannina et al. 2016b). Each model has been calibrated as in Mannina et al. 2011. By comparing measured and simulated data the efficiency of each model output $\left(\mathrm{E}_{\mathrm{i}}\right)$ and the total model efficiency $\left(\mathrm{E}_{\mathrm{MOD}}\right)$ have been evaluated as proposed by Mannina et al. (2011). 


\subsection{Research Unit 2}

The aim of RU2 was the deepening of the chemical/physical/biological phenomena of and aerobic digestion (AeD) more effectively. To this end, RU2 has designed, built and operated a pilot scale plant for aerobic digestion in order to investigate the GHG emissions in different operating conditions. Moreover, a new Aerobic Digestion Model 1, AeDM1, has been developed (Caivano et al. 2015) to simulate the aerobic digestion processes including also GHG emissions. The biological phenomena taking place in AeD are described by a modified ASMN model (Hiatt and Grady 2008), as proposed by Pocquet et al. (2016).

The AeDM1 model has been calibrated and validated using the data collected during the lab-experimental tests on a pilot-scale aerobic digester performed on June-August 2015. The influent and effluent sludge characteristics (e.g. COD, TSS, $\mathrm{NH}_{4}{ }^{+}, \mathrm{NO}_{2}{ }^{-}$and $\mathrm{NO}_{3}{ }^{-}$) and the kinetic parameters, evaluated by means of the respirometric tests (in collaboration with RU3), were used as input data. The sensitivity analysis (Caivano 2017), carried out by applying the Morris screening method (Morris 1991), on the main kinetic parameters allowed us to individuate the parameters that have a high influence on the model output, ensuring the model calibration.

\subsection{Research Unit 3}

RU3 has linked the operative conditions of the anaerobic digestion (sludge age, sludge concentration, retention time) and the quality of the reactors feed, to the biogas production, energy recovery and GHGs emission. Activities of the RU3 are carried through both experimental and modeling approaches. Data gathered from experimental activities are collected for setting up a database in order to increase knowledge and develop detailed models able to properly predict the observed phenomena. The proposed mathematical model is a modified version of the ADM1 model (Batstone et al. 2002) and it is based on differential mass balance equations for substrates, products and biomasses involved in the anaerobic digestion process. The main novelty of the proposed model consists in applying a surface based kinetics approach (Esposito et al. 2011a) for the hydrolysis process, which is useful when hydrolysis is the rate limiting step of the anaerobic digestion. The model simulates the dynamics of 32 state variables and includes more than 70 parameters.

\section{$2.4 \quad$ Research Unit 4}

The applicability of available kinetic models to the case of a full-scale WWTP in Italy was investigated by RU4. One of the most advanced kinetic models was selected as the test model seen its recent application to another full scale scenario (Guo and Vanrolleghem 2014). The model of the plant was already implemented by the plant manager in WEST (DHI) currently in use for normal plant optimization operation. The selected model describes the production of $\mathrm{N}_{2} \mathrm{O}$ through a single pathway approach (i.e. AOB denitrification) based on Mampaey et al. (2013) with the addition of terms for oxygen limitation and inhibition, and terms for free ammonia (FA) and free nitrous acid (FNA) inhibition. 
The use of Principal Component Analysis (PCA) was chosen as an alternative method for approaching $\mathrm{N}_{2} \mathrm{O}$ emission modelling to investigate for an alternative to the current kinetic models. Indeed, the large quantity of available data makes possible to look for hidden relations between operational variables and $\mathrm{N}_{2} \mathrm{O}$ emission. Therefore, a dataset from a field measurement campaign and SCADA data available from a WWTP were used to build a PCA-based statistical model.

\section{Results and Discussion}

\subsection{Research Unit 1}

Findings showed a general improvement of the model output efficiency between Model II and Model III. This result is mainly evident for the aerated reactors thus demonstrating that detailing the $\mathrm{N}_{2} \mathrm{O}$ formation process during nitrification has led to the improvement of the model results. Data of Fig. 1 show a good agreement between measured and modelled value. However, an overestimation of simulated data occurred for the three models, excepting two cases, both for dissolved and off-gas $\mathrm{N}_{2} \mathrm{O}$. This result is likely debited to the discrete sampling. Continuous sampling would improve the results
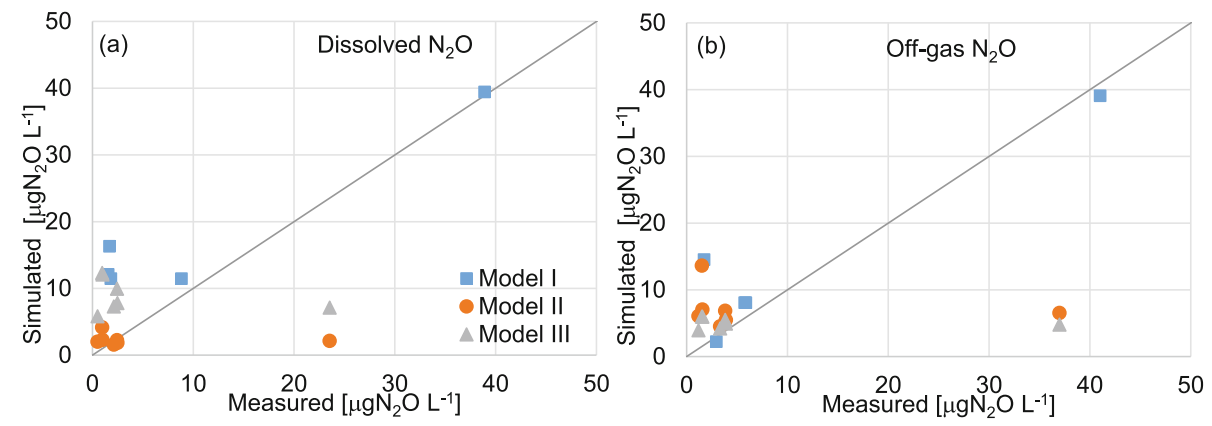

Fig. 1. Measured versus simulated data for each model of the dissolved $\mathrm{N}_{2} \mathrm{O}$ (a) and off-gas $\mathrm{N}_{2} \mathrm{O}(\mathrm{b})$ concentration

\subsection{Research Unit 2}

The maximum specific growth rate of heterotrophs $\left(\mathrm{mu}_{-} \mathrm{H}\right)$ is the more sensitive parameter for all the model outputs. Therefore, the variation, as well as its interaction with the parameters kept fixed at their baseline value, determines a variation of $\mathrm{NO}_{2}{ }^{-}$, $\mathrm{NO}_{3}{ }^{-}, \mathrm{NH}_{2} \mathrm{OH}$, and $\mathrm{N}_{2} \mathrm{O}$ (Caivano 2017).

The comparison between the model output and the lab-measurements (Fig. 2) showed the reliability of the constructed model, including the estimation of the $\mathrm{N}_{2} \mathrm{O}$ emissions. 

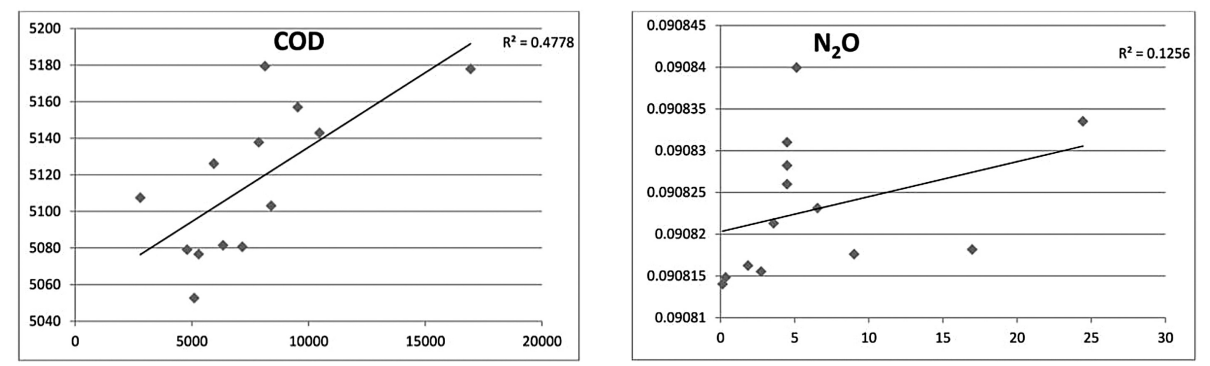

Fig. 2. Example of the model validation

\subsection{Research Unit 3}

A sensitivity analysis for 75 model parameters has been performed by using a derivative method in order to investigate their effects on simulation outputs. Model calibration was used to estimate the surface based kinetic constant, $\mathrm{K}_{\mathrm{sbk}}$, by adopting the protocol introduced by Esposito et al. (2011b) and comparing model results with experimental measurements of methane production from sewage sludge of different WWTP technologies (e.g. MBR and CAS). Comparison between experimental data and modelling results after calibration is reported in Fig. 3.

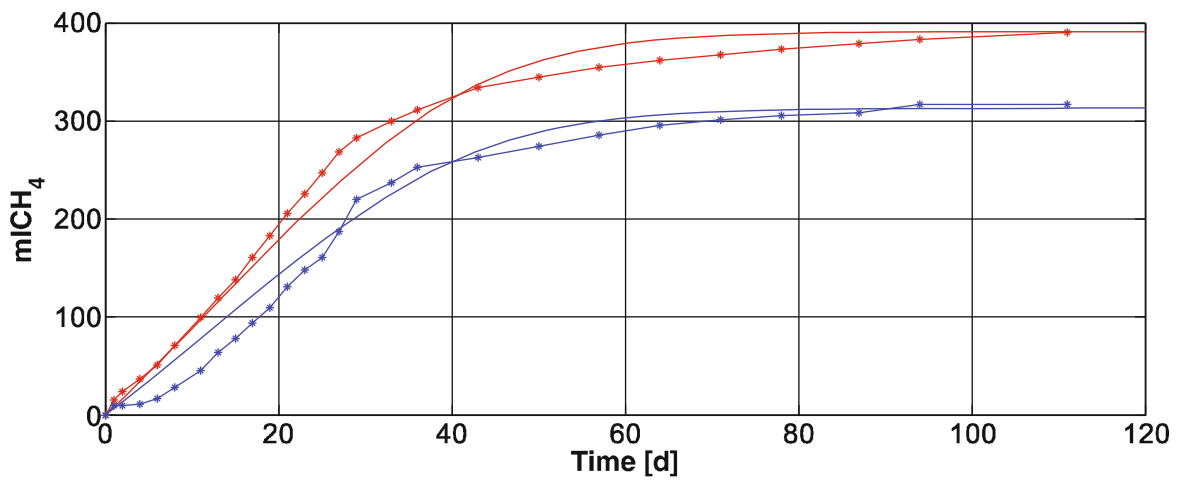

Fig. 3. Comparison between experimental data and modelling results after calibration: red-continuous line is modelled CAS biogas production, red-starred line is experimental CAS biogas production; blue-continuous line is modelled MBR biogas production, blue-starred line is experimental MBR biogas production

\subsection{Research Unit 4}

Results of the measurement campaign were used for developing a stochastic model based on PCA that could be implemented to estimate and mitigate $\mathrm{N}_{2} \mathrm{O}$ emissions. Long datasets of different parameters recorded during the measurement campaigns and other plant data acquired, in parallel, by the WWTP SCADA system, were used to 
mine hidden information about $\mathrm{N}_{2} \mathrm{O}$ production. This information was unravelled using a combination of data processing methods and mathematical tools available in literature.

Results show that even only $\mathrm{DO}, \mathrm{NH}_{4}$ and $\mathrm{NO}_{3}$ (known to be the most meaningful variables for $\mathrm{N}_{2} \mathrm{O}$ emissions among the ones normally monitored in a SCADA system) could manage to cluster high $\mathrm{N}_{2} \mathrm{O}$ emissions data (Fig. 4).



Fig. 4. Example of the application of the statistical PCA model to a full scale dataset

\section{Conclusion}

Traditionally, WWTPs have had the aim of meeting the quality standards of effluent, ensuring a high quality of water bodies and sustainable management costs. However, in recent years, the wastewater treatment objectives have been expanded and include the reduction of greenhouse gas emissions, as a result of the growing concern about climate change and environmental protection. Therefore, it is necessary to develop innovative approaches for an integrated WWTP management system. The collected database of measurements allowed us to develop and apply models of biological processes occurring in the water line and the sludge line of conventional and advanced treatment systems.

The main preliminary conclusions are summarises in the following:

- Concerning the modelling of the MBR treatment, $\mathrm{N}_{2} \mathrm{O}$ formation process during nitrification has led to the improvement of the model results.

- $\mathrm{N}_{2} \mathrm{O}$ emission from AeD mainly depends on the maximum specific growth rates of heterotrophs, ammonia-oxidizing bacteria and nitrite-oxidizing bacteria and on the growth yield of heterotrophs. 
- The mathematical model for anaerobic digestion is useful when hydrolysis is the rate limiting step of the anaerobic digestion.

- The obtained findings derived for full-scale modelling application, highlight the capabilities of online data when combined to full-scale measurements..

Acknowledgments. This research was funded by the Italian Ministry of Education, University and Research (MIUR) through the Research project of national interest PRIN2012 (D.M. 28 dicembre 2012 n. 957/Ric - Prot. 2012PTZAMC) entitled "Energy consumption and GreenHouse Gas (GHG) emissions in the wastewater treatment plants: a decision support system for planning and management" in which Giorgio Mannina is the Principal Investigator and Donatella Caniani, Giovanni Esposito and Riccardo Gori are the coordinators of the research units.

\section{References}

Batstone DJ, Keller J, Angelidaki I, Kalyuzhnyi SV, Pavlostathis SV, Rozzi A et al (2002) Anaerobic digestion model no.1, Rep. No. 13. IWA Publishing, London, p 74

Caivano M, Saluzzi F, Caniani D, Masi S, Mannina G (2015) Development of an aerobic digestion model for the assessment of greenhouse gases production (AeDMG1): Calibration and validation. In: EuroMed 2015 Desalination for Clean Water and Energy Cooperation among Mediterranean Countries of Europe and the MENA Region, Palermo

Caivano M, Masi S, Mazzone G, Mancini IM, Caniani D (2017) Quantification of CO2 and N2O emissions from a pilot-scale aerobic digester, towards the validation and calibration of the first Activated Sludge Model for aerobic digestion (AeDM1). In FICWTM 2017: Frontiers International Conference on Wastewater Treatment, 21-24 May 2017, Palermo, Italy

Caniani D, Esposito G, Gori R, Mannina G (2015) Towards a new decision support system for design, management and operation of wastewater treatment plants for the reduction of greenhouse gases emission. Water 7:5599-5616, doi:10.3390/w7105599

Daelman MRJ, van Voorthuizen EM, van Dongen LGJM, Volcke EIP, van Loosdrecht MCM (2013) Methane and nitrous oxide emissions from municipal wastewater treatment - results from a long-term study. Water Sci Technol 67:2350

Esposito G, Frunzo L, Panico A, Pirozzi F (2011a) Modelling the effect of the OLR and OFMSW particle size on the performances of an anaerobic co-digestion reactor. Process Biochem 46 (2):557-565

Esposito G, Frunzo L, Panico A, Pirozzi F (2011b) Model calibration and validation for OFMSW and sewage sludge co-digestion reactors. Waste Manag 31(12):2527-2535

Guo LS, Vanrolleghem PA (2014) Calibration and validation of an activated sludge model for greenhouse gases no. 1 (ASMG1): prediction of temperature-dependent $\mathrm{N} 2 \mathrm{O}$ emission dynamics. Bioprocess Biosyst Eng 37:151-163

Henze M, Gujer W, Mino T, Van Loosdrecht MCM (2000) Activated sludge models ASM1, ASM2, ASM2d and ASM3. In: IWA Task Group on Mathematical Modelling for Design and Operation of Biological Wastewater Treatment. IWA Publishing, London, UK

Hiatt WC, Grady Jr CPL (2008) An updated process model for carbon oxidation, nitrification, and denitrification. Water Environ Res 80:2145-2156

Mampaey KE, Beuckels B, Kampschreur MJ, Kleerebezem R, van Loosdrecht MCM, Volcke EIP (2013) Modelling nitrous and nitric oxide emissions by autotrophic ammonia-oxidizing bacteria. Environ Technol 34(12):1555-1566 
Mannina G, Ekama G, Caniani D, Cosenza A, Esposito G, Gori R, Garrido-Baserba M, Rosso D, Olsson G (2016a) Greenhouse gases from wastewater treatment - A review of modelling tools. Sci Total Environ 551-552:254-270

Mannina G, Capodici M, Cosenza A, Di Trapani D (2016b) Carbon and nutrient biological removal in a University of Cape Town membrane bioreactor: Analysis of a pilot plant operated under two different C/N ratios. Chem Eng J 296:289-299

Mannina G, Capodici M, Cosenza A, Di Trapani D, Viviani G (2016c) Sequential batch membrane bioreactor for wastewater treatment: effect of salinity increase. Bioresour Technol 209:205-212

Mannina G, Cosenza A, Vanrolleghem PA, Viviani G (2011) A practical protocol for calibration of nutrient removal wastewater treatment models. J Hydroinformatics 13(4):575-595

Morris MD (1991) Factorial sampling plans for preliminary computational experiments. Technometrics 33(2):161e174

Olsson G (2012) ICA and me - A subjective review. Water Res 46:1585-1624

Pocquet M, Wu Z, Queinnec I, Spérandio M (2016) A two pathway model for $\mathrm{N}_{2} \mathrm{O}$ emissions by ammonium oxidizing bacteria supported by the $\mathrm{NO} / \mathrm{N}_{2} \mathrm{O}$ variation. Water Res 88:948-959 